\title{
A Direct Comparison of the Prevalence of Advanced Adenoma and Cancer between Surveillance and Screening Colonoscopies
}

\author{
Alexander Crispin ${ }^{\mathrm{a}} \quad$ Ulrich Mansmann ${ }^{\mathrm{a}} \quad$ Axel Munte $^{\mathrm{b}} \quad$ Mark op den Winkel $^{\mathrm{c}}$ \\ Burkhard Göke ${ }^{c}$ Frank Thomas Kolligs ${ }^{c}$ \\ ${ }^{a}$ Institute of Medical Informatics, Biometry, and Epidemiology, ${ }^{b}$ Bavarian Association of Compulsory Health \\ Insurance Physicians, and ' Department of Medicine II, Munich, Germany
}

\section{Key Words}

Colorectal cancer · Surveillance $\cdot$ Advanced adenoma

\begin{abstract}
Background/Aims: Surveillance colonoscopy is recommended after polypectomy of adenoma and surgery for colorectal cancer. The purpose of this study was to assess the frequency of advanced adenoma and cancer in colonoscopies performed for surveillance compared to screening colonoscopies. Methods: Analysis of relative frequencies of findings in colonoscopies performed for post-adenoma surveillance (post-ad), post-cancer surveillance (post-crc), screening, and follow-up of a positive fecal occult blood test (FOBT). Logistic regression was used to identify the risk for advanced adenoma (adenoma $\geq 10 \mathrm{~mm}$, containing highgrade dysplasia, or villous histology) and cancer. Results: 324,912 colonoscopies were included in the analysis: 81,877 post-ad, 26,896 post-crc, 178,305 screening, 37,834 positive FOBT. Advanced adenoma (cancer) was diagnosed in $8.0 \%$ $(0.4 \%)$ of post-ad, $5.0 \%(1.0 \%)$ of post-crc, $7.4 \%(1.1 \%)$ of screening, and $11.7 \%$ (3.6\%) of positive FOBT colonoscopies. Compared to screening, the odds ratios for finding advanced adenoma were $0.93(95 \% \mathrm{Cl}$ 0.88-0.98) for post-ad, 0.96 (0.86-1.08) for post-crc, and 1.18 (1.09-1.28) for positive FOBT colonoscopies. The odds ratios for the diagnosis of
\end{abstract}

\section{KARGER}

E-Mail karger@karger.com www.karger.com/dig cancer were $0.29(0.24-0.36)$ for post-ad, 0.81 (0.61-1.07) for post-crc, and 2.77 (2.43-3.17) for positive FOBT. Conclusion: Colonoscopy for post-ad surveillance but not colonoscopy for post-crc surveillance is associated with a lower risk of diagnosis of advanced adenoma and cancer.

Copyright $\odot 2013$ S. Karger AG, Basel

\section{Introduction}

Colorectal cancer is among the most frequent causes of cancer-related morbidity and mortality $[1,2]$. Screening of asymptomatic individuals has been recommended by national and international guidelines [3-5]. Colonoscopy is performed either as the primary screening or for the work-up of individuals with positive fecal occult blood test (FOBT), sigmoidoscopy, or virtual colonography. Cohort studies have demonstrated a reduction of incidence and mortality from colorectal cancer after colonoscopic polypectomy $[6,7]$. Surveillance by colonoscopy is recommended in defined intervals after curative resection of colorectal cancer and after endoscopic removal of adenomatous polyps to detect metachronous cancer and adenoma $[4,8,9]$. It has been demonstrated that the frequency of metachronous cancer detected upon surveillance colonoscopy after resection of colorectal 
Table 1. Demographic characteristics

\begin{tabular}{lc}
\hline Characteristic & Individuals, $\mathrm{n}(\%)$ \\
\hline Total & $324,912(100.00)$ \\
Age group, years & \\
$\quad \leq 64$ years & $158,788(48.9)$ \\
$\quad \geq 65$ years & $166,124(51.1)$ \\
Sex & \\
$\quad$ Male & $155,306(47.8)$ \\
$\quad$ Female & $169,606(52.2)$ \\
Indication for colonoscopy & \\
$\quad$ Primary screening colonoscopy & $178,305(54.9)$ \\
$\quad$ FOBT+ work-up colonoscopy & $37,834(11.6)$ \\
$\quad$ Post-adenoma surveillance colonoscopy & $81,877(25.2)$ \\
$\quad$ Post-cancer surveillance colonoscopy & $26,896(8.3)$ \\
\hline
\end{tabular}

cancer is comparable with the rate of cancers detected upon screening colonoscopy [8]. Studies on the risk of metachronous cancer after polypectomy have yielded discordant results: some studies have reported an increased risk [10-14], others have reported a reduced risk $[6,15-17]$.

So far the frequency and risk of metachronous cancer and advanced adenoma upon post-cancer and post-adenoma surveillance have not been assessed in the same study. To determine the risk of advanced adenoma and cancer in surveillance colonoscopies, we analyzed a large sample of colonoscopies done for surveillance after curative resection of colorectal cancer or removal of colonic adenomas. We determined the relative frequencies of findings and calculated the risk of advanced adenoma and cancer in surveillance colonoscopies.

\section{Material and Methods}

\section{Colonoscopy Registry}

The Bavarian Association of Compulsory Health Insurance (CHI) Physicians documents all outpatient colonoscopies in a central database. Only endoscopists with a documented experience of $\geq 200$ colonoscopies and $\geq 50$ polypectomies within the past 2 years and a continuously high volume of colonoscopies and polypectomies are certified to perform colonoscopies in outpatients insured by the CHI system covering about $83 \%$ of the Bavarian population. Online documentation is required for reimbursement. No individual patient identification data are contained in the database and data collection has been approved by the Bavarian governmental authority for data protection. For this analysis, datasets of all colonoscopies performed in adults for primary screening, for follow-up on a positive FOBT, for post-cancer or post-adenoma surveillance between January 2006 and December 2008 were available. The findings on colonoscopy were

Advanced Adenoma and Cancer in

Surveillance Colonoscopies
Table 2. Characteristics of colonoscopies

\begin{tabular}{lc}
\hline Characteristic & Colonoscopies, $\mathrm{n}(\%)$ \\
\hline Sedation & $299,021(92.03)$ \\
Cecum rate & $318,182(97.93)$ \\
Incomplete due to & $795(0.24)$ \\
$\quad$ Remaining stool & $1,356(0.42)$ \\
Stenosis & $571(0.18)$ \\
Pain & $83(0.03)$ \\
Complication & $3,925(1.21)$ \\
Other & $680(0.21)$ \\
Complication & $88(0.03)$ \\
Bleeding & $126(0.04)$ \\
Perforation & \\
Cardiopulmonary
\end{tabular}

categorized on the basis of the most advanced lesion found. Colonoscopies done in individuals younger than 18 years, individuals with a history of chronic inflammatory bowel disease, individuals with increased family risk, and repeat examinations were excluded from analysis. In case of repeat examinations only the index colonoscopy was included. Advanced adenoma was defined as adenoma that was at least $10 \mathrm{~mm}$ in diameter, had high-grade dysplasia, had villous or tubulovillous histologic characteristics, or any combination thereof.

\section{Statistical Analysis}

Distributions of characteristics of patients, colonoscopies, complications, and detected lesions were described using absolute and relative frequencies. Adenoma detection rates were defined as the proportions of subjects in whom at least one adenoma was identified. We modeled the risks of advanced adenoma and cancer in patients with lesions using logistic regression models including the following fixed set of independent variables: lesion count, size of the largest lesion, localization of the largest lesion, gender, age, age squared, age cubed, and indication for colonoscopy. All analyses were performed using SAS version 9.2 for Linux (SAS Institute, Inc., Cary, N.C., USA).

\section{Results}

For this analysis, a total of 324,912 colonoscopies performed in adults were included (table 1). 158,788 (48.9\%) individuals were $\leq 64$ years and $166,124(51.1 \%)$ were $\geq 65$ years, $169,606(52.2 \%)$ were female and $155,306(47.8 \%)$ were male. 81,877 (25.2\%) colonoscopies were done for post-adenoma surveillance, $26,896(8.3 \%)$ colonoscopies were done for post-cancer surveillance, 178,305 (54.9\%) colonoscopies were primary screening studies, and 37,834 (11.6\%) colonoscopies were done for work-up of a positive FOBT. 299,021 (92.03\%) colonoscopies were done under sedation (table 2). In 318,182 (97.93\%) colono- 


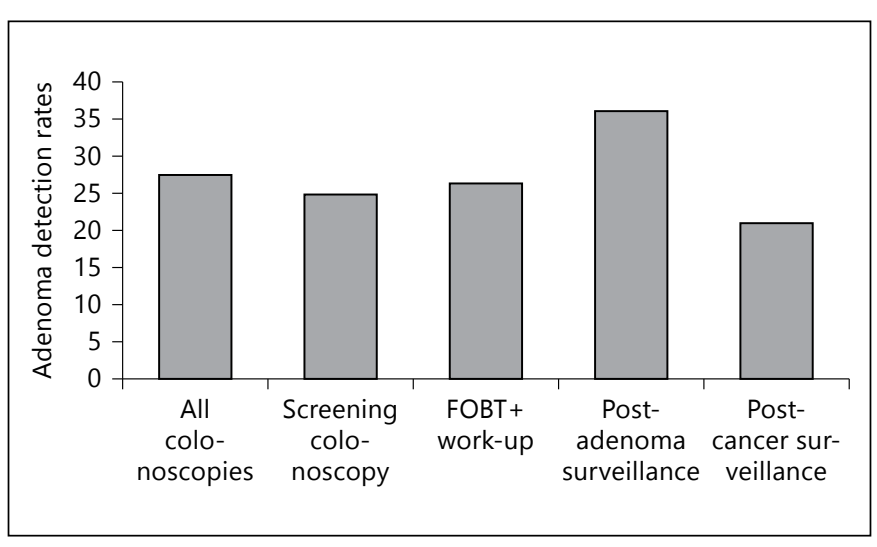

Fig. 1. Adenoma detection rates.

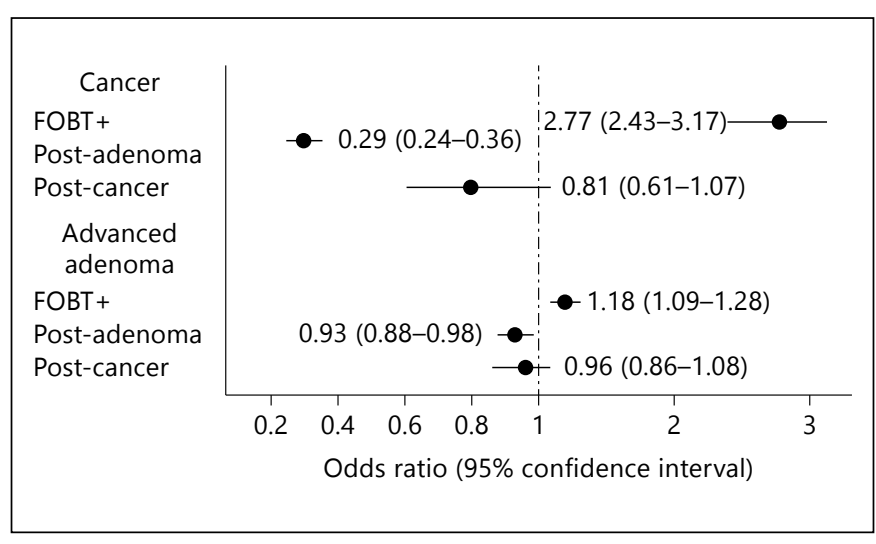

Fig. 2. Odds ratios for the diagnosis of cancer and advanced adenoma as compared to primary colonoscopy screening. The dashed vertical line represents the odds ratio of screening colonoscopy.

Table 3. Neoplastic lesions found according to indication for colonoscopy

\begin{tabular}{|c|c|c|c|c|c|}
\hline & $\begin{array}{l}\text { Total } \\
\mathrm{n}(\%)\end{array}$ & $\begin{array}{l}\text { Screening } \\
\text { colonoscopies } \\
\mathrm{n}(\%)\end{array}$ & $\begin{array}{l}\text { FOBT+ work-up } \\
\text { colonoscopies } \\
\text { n }(\%)\end{array}$ & $\begin{array}{l}\text { Post-adenoma } \\
\text { surveillance } \\
\mathrm{n}(\%)\end{array}$ & $\begin{array}{l}\text { Post-cancer } \\
\text { surveillance } \\
\mathrm{n}(\%)\end{array}$ \\
\hline Number of colonoscopies & $324,912(100.00)$ & $178,305(100.00)$ & $37,834(100.00)$ & $81,877(100.00)$ & $26,896(100.00)$ \\
\hline Non-advanced adenoma & $63,621(19.58)$ & $31,084(17.43)$ & $5,513(14.57)$ & $22,815(27.87)$ & $4,209(15.65)$ \\
\hline Advanced adenoma & $25,580(7.87)$ & $13,215(7.41)$ & $4,432(11.71)$ & $6,583(8.04)$ & $1,350(5.02)$ \\
\hline Cancer & $3,808(1.17)$ & $1,865(1.05)$ & $1,369(3.62)$ & $297(0.36)$ & $277(1.03)$ \\
\hline
\end{tabular}

scopies the cecum was reached. The colonoscopy was incomplete due to remaining stool in $795(0.24 \%)$, due to stenosis in $1,356(0.42 \%)$, due to pain in $571(0.18 \%)$, due to complications in $83(0.03 \%)$, and due to other reasons in $3,925(1.21 \%)$ of cases. A complication occurred in $894(0.28 \%)$ colonoscopies: 680 bleedings $(0.21 \%), 88$ perforations $(0.03 \%)$, and $126(0.04 \%)$ cardiopulmonary complications.

$63,621(19.58 \%)$ of the colonoscopies revealed nonadvanced adenomas, 25,580 (7.78\%) revealed advanced adenomas, and 3,808 (1.17\%) revealed cancers (table 3 ). The adenoma detection rates of all colonoscopies were 27.5\%: $24.9 \%$ for screening colonoscopies, $26.3 \%$ for work-ups for positive FOBT, 35.9\% for post-adenoma surveillance, and $20.7 \%$ for post-cancer surveillance (fig. 1). Of the 178,305 screening colonoscopies, 31,084 $(17.43 \%)$ reported non-advanced adenomas, 13,215 (7.41\%) reported advanced adenomas, and 1,865 (1.05\%) reported cancers as the most advanced lesion found. $5,513(14.57 \%)$ of the 37,834 colonoscopies done for follow-up of a positive FOBT identified non-advanced ad- enomas, 4,432 (11.71\%) advanced adenomas, and 1,369 (3.62\%) cancers. 81,877 colonoscopies done for postadenoma surveillance revealed 22,815 (27.87\%) non-advanced adenomas, 6,583 (8.04\%) advanced adenomas, and $297(0.36 \%)$ cancers. The 26,896 colonoscopies performed for post-cancer surveillance identified 4,209 (15.65\%) non-advanced adenomas, 1,350 (5.02\%) advanced adenomas, and 277 (1.03\%) cancers.

Logistic regression was performed to identify the risk for cancer and advanced adenoma in surveillance colonoscopies (fig. 2). Colonoscopies done for post-adenoma surveillance were associated with a lower risk of carrying cancer (OR 0.29; 95\% CI 0.24-0.36) or advanced adenoma (OR 0.93; 95\% CI 0.88-0.98) than screening colonoscopies. The risk of finding cancer (OR 0.81; 95\% CI 0.611.07 ) or advanced adenoma (OR 0.96 ; 95\% CI 0.86-1.08) upon colonoscopy was similar for post-cancer surveillance and screening. Compared to screening colonoscopies, FOBT follow-up colonoscopies were associated with the highest risk of finding cancer (OR 2.77; 95\% CI 2.433.17) or advanced adenoma (OR 1.18; 95\% CI 1.09-1.28). 


\section{Discussion}

The present study is based on a large cohort of routine surveillance colonoscopies done in unselected individuals. The study analyzes the risk of advanced adenoma and cancer in post-cancer and post-adenoma surveillance in parallel to screening colonoscopies, representing a group of individuals at average risk, and colonoscopies done for work-up of positive FOBTs, representing a group at increased risk. Colonoscopies done in individuals with a known increased family risk for colorectal cancer were excluded to avoid a bias due to different basic risks. The quality of the colonoscopies documented in the database is highly reflected by a low complication rate, a high rate of complete examinations, and adenoma detection rates above $20 \%$. We demonstrate that colonoscopies done for post-adenoma surveillance are associated with a reduced risk of advanced adenoma and cancer compared to screening colonoscopy. Individuals undergoing postcancer surveillance have a similar risk for advanced adenoma and cancer as individuals undergoing screening. As expected, colonoscopies done for follow-up of a positive FOBT, representing a high-risk group, had the highest risk for advanced adenoma and cancer.

An adenoma detection rate of $20 \%$ or higher has been demonstrated to be associated with the lowest risk of interval colorectal cancer after screening colonoscopy [18]. In the same study the cecal intubation rate was not significantly associated with this risk. The adenoma detection rate was above $20 \%$ in all of the four colonoscopy indication groups in our study, demonstrating the high quality of the colonoscopists. However, it was highest in the post-adenoma surveillance group with $35.9 \%$ and lowest in the post-cancer surveillance group with $20.7 \%$. As these colonoscopies have been performed by the same endoscopists there is no reason to assume a difference in the quality of the colonoscopies. A potential and possibly most likely explanation for the lowest adenoma detection rate in the post-cancer surveillance group is the status of partial or hemicolectomy due to the history of cancer resulting in a reduced total colonic surface. The high adenoma detection rate in the post-adenoma surveillance group is mainly due to the high number of non-advanced adenomas resulting in a non-advanced-to-advanced adenoma ratio of 3.5 compared to a ratio of 2.4 in the screening group. An even higher adenoma detection rate of $39.7 \%$ and a similarly high ratio of 2.9 have previously been reported in a cohort of post-adenoma surveillance colonoscopies [14].

Advanced Adenoma and Cancer in

Surveillance Colonoscopies
The rationale for surveillance after polypectomy is that size, number and histology of adenoma at baseline colonoscopy indicate the risk for the development of metachronous cancer and advanced adenoma [9]. We find that colonoscopies performed for post-adenoma surveillance are associated with a significantly lower risk of finding cancer or advanced adenoma than screening colonoscopies. This might indicate a protective effect of clearing the colon of adenomas during a prior colonoscopy. Our frequencies of findings are in line with other studies, for example Cottet et al. [14] reported on 4,881 colonoscopies done for surveillance after removal of adenoma: $29.6 \%$ colonoscopies revealed a non-advanced adenoma, $10.1 \%$ an advanced adenoma, and $0.1 \%$ cancer as the most advanced lesion found. The researchers of the National Polyp Study reported on $26.6 \%$ non-advanced adenomas upon the first surveillance colonoscopy and $20.7 \%$ non-advanced adenomas upon the second surveillance colonoscopy [19]. However, the rates of advanced adenoma were 2.9 and $0.9 \%$ in this study, respectively. This stands in strong contrast to our and Cottet's findings and is most likely due to the fact that the numbers reported by Winawer et al. [19] are based on a trial while our and Cottet's studies are based on routine colonoscopies. Still the high rate of non-advanced adenomas in all three studies may be explained by an increased risk for developing adenoma after polypectomy supporting the surveillance recommendations. Furthermore, due to surveillance, these earlier adenomas might not have had the time to advance in size and towards more severe histological abnormalities. Another issue that needs to be discussed in this context is that colonoscopy misses a substantial number of small lesions as has been demonstrated by back-to-back colonoscopy studies [20]. Therefore, it cannot be excluded that the high number of nonadvanced adenomas in the surveillance groups is at least in part due to failure of colonoscopy to detect and remove these lesions at baseline colonoscopy. We find a strongly reduced risk of cancer in the post-adenoma surveillance group compared to the screening group which can be assumed to be at average risk. Cottet et al. [14] reported on an increased risk of colorectal cancer after polypectomy compared to the expected number of cases. However, a significant difference was only seen in the group of individuals with advanced adenoma at baseline colonoscopy who did not have surveillance colonoscopy but not in the group that received surveillance colonoscopies. This group was shown to be at similar risk as the general population. Several other studies have also reported on the cancer risk after removal of adenoma. Studies reporting 
on cohorts of populations without surveillance have reported on an increased risk [10-13] while a reduced risk has been reported in studies with systematic surveillance after polypectomy [6, 15-17]. Therefore, polypectomy in combination with surveillance colonoscopy and not polypectomy alone appears to reduce the risk of colorectal cancer.

Surveillance colonoscopy in patients after resection of colorectal cancer intends to detect early recurrences of the resected cancers and to detect metachronous cancers [20]. Anastomotic recurrences have been demonstrated to be less frequent in colon than in rectal cancer patients. It has been shown that the risk of a second colorectal cancer remains high after curative resection of colorectal cancer [21]. A meta-analysis has found that the rate of metachronous cancers detected upon surveillance compares very well with the rate of prevalent cancers detected during screening colonoscopy [20]. However, some of the cancers detected, especially those detected early after resection, may represent synchronous lesions missed at the time of the initial diagnosis. There are at least three potential reasons for the higher cancer rate in the post-cancer than in the post-adenoma surveillance group: (1) compliance with surveillance recommendations may have differed between groups; (2) patients with a history of cancer may differ biologically from patients with adenomatous polyps and may therefore have a higher risk, and (3) clearing of the colon from adenoma may not have been as rigorous in the initial colonoscopy in the cancer as in the adenoma group. Our study does not give the answer, however it reconfirms the necessity for surveillance after surgery for colorectal cancer. Future studies need to clarify this dilemma and how to further reduce the risk of metachronous cancer.

Three major issues related to the database underlying this analysis limit the conclusions that may be drawn from this study. First, we do not know the time interval since resection of the cancer or removal of the adenoma and surveillance colonoscopy. Furthermore, we do not know whether the surveillance colonoscopy documented in the database was the first or a repeat examination after resection of the cancer or removal of the adenoma. The risk of advanced adenoma and cancer may be different in a first compared to a repeat surveillance colonoscopy. Therefore, our study is only able to give mean numbers for first and repeat surveillance colonoscopies. Future database documentation should account for this. Second, our study is a retrolective analysis of routine data not primarily collected for scientific purposes, such as the analysis of risk for advanced adenoma and cancer in surveil- lance colonoscopies. A negative consequence of this is that we neither know the stage of the original tumor in the post-cancer surveillance group, nor the size, number and histology of adenomas removed in the post-adenoma surveillance group. As size, histology, and multiplicity of the polyps removed at baseline colonoscopy predict the subsequent detection of advanced adenomas [9], this would have been important information. Accordingly, guidelines recommend surveillance colonoscopy 3 years after removal of advanced adenomas and 5 years after removal of non-advanced adenomas. Moreover, patients with 3 or more adenomas of any size are also assumed at increased risk of advanced adenomas and therefore recommended surveillance colonoscopy after 3 years [9]. This limitation can best be overcome by prospective studies. Documentation of this information in the database would improve future analyses. Third, another limitation is that histology was performed by local pathologists and not subject to central review. Systematic over- or underreading of advanced histology could introduce bias. However, in another study employing central pathology review of local pathology interpretation, a systematic bias was not detected [22].

In conclusion, this study demonstrates that the risk of advanced adenoma and cancer remains at the same level after resection of cancer as in an average risk population undergoing screening colonoscopy. This reinforces the importance of regular surveillance in this subgroup of patients. Furthermore, the risk of advanced adenoma is slightly and the risk of cancer is strongly reduced in individuals after prior removal of colorectal adenoma. The strong reduction of risk for colorectal cancer lends further support to the efficacy of colonoscopy in combination with polypectomy in preventing colorectal cancer. As the risk for advanced adenoma is only slightly reduced in this subgroup of patients and advanced adenomas bear a high potential of malignant transformation, surveillance colonoscopies also need to be done regularly in this subgroup.

\section{Acknowledgements}

Support by the LMUinnovativ Project, Munich Center of Health Sciences, Subproject II (evidence-based prevention and modeling of chronic diseases) is gratefully acknowledged.

\section{Disclosure Statement}

The authors have no conflicts of interest to disclose. 


\section{References}

1 Jemal A, Siegel R, Ward E, et al: Cancer statistics, 2009. CA Cancer J Clin 2009;59:225-249.

$>2$ Parkin DM, Bray F, Ferlay J, et al: Global cancer statistics, 2002. CA Cancer J Clin 2005;55: 74-108.

$>3$ Levin B, Lieberman DA, McFarland B, et al: Screening and surveillance for the early detection of colorectal cancer and adenomatous polyps, 2008: a joint guideline from the American Cancer Society, the US Multi-Society Task Force on Colorectal Cancer, and the American College of Radiology. Gastroenterology 2008;134:1570-1595.

$>4$ Schmiegel W, Reinacher-Schick A, Arnold D, et al: Update S3 guideline 'colorectal cancer' 2008 (in German). Z Gastroenterol 2008;46: 799-840.

5 Segnan N, Patnick J, von Karsa L: European guidelines for quality assurance in colorectal cancer screening and diagnosis. http://screening.iarc.fr/doc/ND3210390ENC.pdf $\quad$ (accessed May 4, 2012).

6 Winawer SJ, Zauber AG, Ho MN, et al: Prevention of colorectal cancer by colonoscopic polypectomy. The National Polyp Study Workgroup. N Engl J Med 1993;329:19771981.

7 Zauber AG, Winawer SJ, O’Brien MJ, et al: Colonoscopic polypectomy and long-term prevention of colorectal-cancer deaths. N Engl J Med 2012;366:687-696.
8 Rex DK, Kahi CJ, Levin B, et al: Guidelines for colonoscopy surveillance after cancer resection: a consensus update by the American Cancer Society and the US Multi-Society Task Force on Colorectal Cancer. Gastroenterology 2006;130:1865-1871.

$>9$ Winawer SJ, Zauber AG, Fletcher RH, et al: Guidelines for colonoscopy surveillance after polypectomy: a consensus update by the US Multi-Society Task Force on Colorectal Cancer and the American Cancer Society. Gastroenterology 2006;130:1872-1885.

$>10$ Atkin WS, Morson BC, Cuzick J: Long-term risk of colorectal cancer after excision of rectosigmoid adenomas. N Engl J Med 1992;326: 658-662.

11 Simons BD, Morrison AS, Lev R, et al: Relationship of polyps to cancer of the large intestine. J Natl Cancer Inst 1992;84:962-966.

12 Levi F, Randimbison L, La Vecchia C: Trends in subsite distribution of colorectal cancers and polyps from the Vaud Cancer Registry. Cancer 1993;72:46-50.

13 Loeve F, van Ballegooijen M, Boer R, et al: Colorectal cancer risk in adenoma patients: a nation-wide study. Int J Cancer 2004;111: 147-151.

14 Cottet V, Jooste V, Fournel I, et al: Long-term risk of colorectal cancer after adenoma removal: a population-based cohort study. Gut 2012;61:1180-1186.

$>15$ Jorgensen OD, Kronborg O, Fenger C: The Funen Adenoma Follow-Up Study. Incidence and death from colorectal carcinoma in an adenoma surveillance program. Scand J Gastroenterol 1993;28:869-874.
16 Lund JN, Scholefield JH, Grainge MJ, et al: Risks, costs, and compliance limit colorectal adenoma surveillance: lessons from a randomised trial. Gut 2001;49:91-96.

17 Bertario L, Russo A, Sala P, et al: Predictors of metachronous colorectal neoplasms in sporadic adenoma patients. Int J Cancer 2003; 105:82-87.

18 Kaminski MF, Regula J, Kraszewska E, et al: Quality indicators for colonoscopy and the risk of interval cancer. N Engl J Med 2010;362: 1795-1803.

19 Winawer SJ, Zauber AG, O’Brien MJ, et al: Randomized comparison of surveillance intervals after colonoscopic removal of newly diagnosed adenomatous polyps. The National Polyp Study Workgroup. N Engl J Med 1993;328:901-906.

20 Rex DK, Cutler CS, Lemmel GT, et al: Colonoscopic miss rates of adenomas determined by back-to-back colonoscopies. Gastroenterology 1997;112:24-28.

21 Green RJ, Metlay JP, Propert K, et al: Surveillance for second primary colorectal cancer after adjuvant chemotherapy: an analysis of Intergroup 0089. Ann Intern Med 2002;136: 261-269.

22 Lieberman D, Moravec M, Holub J, et al: Polyp size and advanced histology in patients undergoing colonoscopy screening: implications for CT colonography. Gastroenterology 2008;135:1100-1105. 